\title{
Plastic food contact articles-food chemical safety unwrapped
}

\author{
Shirra Freeman \\ Environmental Health Translation Scientist, National Collaborating Centre for Environmental Health, Vancouver, BC, Canada.
}

\section{Introduction}

Food safety has long been a central focus of environmental public health (EPH) practice (Rayner and Scarborough, 2005). Foodborne-illness surveillance and outbreak investigations conducted by public health departments are often highly effective in mitigating exposure to pathogens. Throughout the food supply system, preventative approaches such as risk assessment and HACCP (Hazard Analysis and Critical Control Point) are used to minimise potential biological, physical, and chemical safety hazards. Four categories of chemical hazards are typically addressed within these approaches: naturally occurring (e.g., poisonous plants, marine toxins), intentionally added (e.g., food additives), unintentionally added (e.g., cleaning chemicals, pesticides), and food allergens (Canadian Food Inspection Agency, 2010; Jenner et al., 2005; U.S. Department of Health and Human Services, 2008).

Another potentially important chemical hazard may be present in plastic items used for the preparation, storage, serving, and consumption of foods within food service and retail establishments overseen by the EPH community. These items are collectively referred to as plastic food contact articles (PFCAs) (Muncke et al., 2017). They are composed of combinations of chemicals, some of which are toxic and may contaminate foods (Hahladakis et al., 2018). Because PFCAs are used extensively, large portions of the population may be at risk of exposure given that within EPH practice there has been limited oversight of this potential hazard.

Food contact with plastic is treated as an issue of emerging concern as there is a growing body of evidence and awareness of a potential public health hazard, even though policy and regulation are not yet comprehensive (Diamond et al., 2011; Halden, 2010, 2015). This paper provides an overview of PFCAs and their uses, assesses concerns and knowledge gaps, reviews regulation, and discusses challenges for EPH practice.

\section{Overview of PFCAs}

PFCAs belong to a large group defined by Muncke et al. (2017) as food contact articles (FCA). They include packaging, containers, surfaces such as cutting boards, and utensils. They may also be part of food processing machinery. PFCAs are inexpensive and multi-functional, thus satisfying the requirements of industry and regulatory compliance for food quality and safety as well as consumer preferences. Hence, they are more prevalent in use

Corresponding author: Shirra Freeman (email: Shirra.freeman@bccdc.ca). than articles made from other materials (e.g., paper, wood, glass, or metal) (Marsh and Bugusu, 2007).

PFCAs are made from resins containing plastic polymers, often combined with additives. The polymers are derived from petroleum products and additives provide specific properties such as flexibility, rigidity, colour, and transparency. The resins are known as Food Contact Materials (PFCMs). Distinguishing PFCAs from PFCMs is important for EPH practice because PFCMs are usually raw materials used to make the articles, whereas PFCAs are vessels and items that operators use. PFCMs and the chemicals used to manufacture them are regulated. In contrast, there is less direct regulatory oversight of PFCAs and it can be difficult to identify the materials used to make them.

PFCAs may be constructed from different PFCMs, e.g., a single-use plastic water bottle can be created from different resins containing at least 13 polymers (Singh et al., 2017). Similarly, the same polymer can be used to manufacture many different articles. For example, low-density polyethylene is used to make food bags, squeezable food bottles, shrink and stretch film, trays, and seals (Grob et al., 2010). Plastic is also found in articles composed of several materials such as metal containers or paper lined with plastic. PFCAs may also contain transformation and breakdown products as well as impurities (Muncke et al., 2017).

\section{PFCA hazards and risks}

The study of plastics and chemical contamination of food began in the 1970s (Vitrac and Goujon, 2014). Currently, of the more than 6000 regulated chemicals in North American and European inventories, most are used to manufacture PFCAs (Geueke et al., 2014; Groh et al., 2018; Oldring et al., 2014). To summarize the current state of knowledge and scope the relevance for EPH practice, this section examines three issues: whether there may be a hazard, whether people may be exposed to the hazard, and whether the exposure risk is unacceptably high.

\section{Hazards of chemicals used in manufacturing PFCAs}

The potential hazards of PFCAs are related to the raw chemical compounds used in the manufacturing process. In peer-reviewed literature on PFCMs and chemical toxicology, Geueke et al. (2014) identified at least 175 hazardous compounds used to manufacture PFCMs. These include 20 monomers, intermediate products, and polymers, as well as over 20 solvents and banned substances such as heavy metals especially in dyes and 
volatile compounds in black plastic. Seven compounds are persistent and bioaccumulative or very persistent and bioaccumulative. Adverse health outcomes have been identified in all major groupings-carcinogenicity, mutagenicity, reproductive, and developmental - for both chronic and acute exposures. All of the major exposure pathways (oral, dermal, respiratory) are potentially involved. Sixty-three human health hazards have been identified with packaging alone, which accounts for approximately $40 \%$ of all PFCA. Hazards may also be associated with chemical mixtures from the compounding of raw materials in manufacturing PFCAs but little is known about this issue (Groh et al., 2018).

\section{Chemical migration from PFCAs to food and potential human exposure}

For PFCAs, the main exposure pathway of concern is oral, i.e., through the consumption of contaminated foods. Food becomes contaminated through a process known as migration that can occur in three ways (Table 1): (i) Chemicals may migrate when foods and monolayer PFCAs are in direct contact. (ii) If a container or package is composed of several layers, chemicals may pass from outer to inner layers and then to food. (iii) Volatile compounds may also pass through the airspace between a PFCA and food.

There are three determinants of migration and its extent: a material's chemical composition, environmental factors, and characteristics of the food matrix. The interaction among the three has been extensively studied within the scientific literature as well as by PFCM regulators (Lechevalier, 2016; Singh et al., 2017). Several heuristics for identifying migration catalysts can be distilled from research findings:

1. Contact time: The longer that food and PFCAs are in contact, the greater the chance of migration.

2. Temperature: Higher temperatures tend to increase migration rates; very low temperatures may alter the stability of a PFCA and increase the likelihood of migration.

3. Food type: Migration rates are higher for fats, acids and liquids in contact with specific PFCAs.

4. Container size: Smaller containers have more plastic surface in contact with food and correspondingly greater migration potential.
5. Physical state: Migration is more likely with older, heavily used, and damaged items.

6. Presence of lubricants: Lubricants tend to have high migration rates.

\section{Potential level of exposure}

Consumers may be exposed to chemical hazards via the migration of chemicals into the food they eat. To determine whether exposures may be unacceptably high, two questions are considered:

1. Are there standards for "safe" exposure levels?

2. Do measured or estimated PFCA-associated exposures exceed these levels?

The answer to the first question is a qualified "Yes". Regulatory limits such as Acceptable Daily Intake and oral Reference Doses exist for many of the toxic migrants discussed above. Some are "as low as reasonably achievable" substances such as certain heavy metals. Another substance, Bisphenol A, a known endocrine disrupting chemical, has been replaced in many PFCAs used with foods and beverages consumed by infants and young children (Environment Canada and Health Canada, 2008). However, other chemicals that constitute raw materials (as single chemicals or mixtures) that are used in manufacturing PFCAs are not regulated. This regulatory gap presents a challenge in fully assessing the safety of the range of plastics in contact with food (Muncke et al., 2017).

It is not possible to fully answer the second question at this time because not enough is known about concentration of hazardous PFCA-related chemicals in foods or about uptake of these chemicals by consumers. A small number of studies have attempted to quantify exposures. One study, conducted between 1983 and 2010 on 1623 samples of plastic food packaging in Taiwan, found that migration was highest from printed inks, rough or cracked surfaces, and polyvinyl chloride in contact with hot or fatty foods (Kao, 2012). This study also indicated that migration could cause unacceptably high exposure levels. Two other studies attempted to model dietary exposures. Duffy et al. (2007) and Holmes et al. (2005) estimated consumption factors for chemicals in food packaging, applying methods similar to those used to estimate dietary exposure to other foodborne chemicals. Both these studies provided insights into methods

Table 1. Mechanisms of chemical migration from PFCAs into food (Source: Vitrac and Goujon, 2014)

\begin{tabular}{|l|l|l|}
\hline $\begin{array}{l}\text { Mechanism of } \\
\text { contamination }\end{array}$ & Description & Examples \\
\hline $\begin{array}{l}\text { Direct contact between food } \\
\text { matrices and PFCAs }\end{array}$ & PFCAs and food items touch each other. & $\begin{array}{l}\text { Food in contact with inner layer or side of wrappings, } \\
\text { packages, and containers; plastic utensils and surfaces } \\
\text { used in preparing and serving food. }\end{array}$ \\
\hline $\begin{array}{l}\text { Indirect contact via the } \\
\text { plastic layer in contact with } \\
\text { food }\end{array}$ & $\begin{array}{l}\text { The chemical substance passes through } \\
\text { one or more materials before } \\
\text { contaminating the food. }\end{array}$ & $\begin{array}{l}\text { Chemical substances located on outer layers of multilayer } \\
\text { PFCA migrate through the inner layer and then to the } \\
\text { food; most common in the case of inks and adhesives used } \\
\text { on packages. }\end{array}$ \\
\hline No physical contact & $\begin{array}{l}\text { Contamination via space between } \\
\text { container and the food matrix } \\
\text { (headspace). }\end{array}$ & $\begin{array}{l}\text { Mainly a concern for volatile substances such as inks, } \\
\text { solvents, and substances used in secondary packaging. }\end{array}$ \\
\hline
\end{tabular}


for quantifying exposures, but did not provide the estimations of population-level exposures.

\section{Policy, regulation, and management of PFCAs in Canada}

Policy and regulation of PFCAs in Canada focus on the materials from which PFCAs are made and the settings in which they are used. As the following two sub-sections explain, chemicals and materials tend to be regulated at the federal level and settings such as food service establishments tend to fall under EPH jurisdictions at provincial and local levels.

\section{Policies and regulations related to materials in PFCAs}

Federal regulation focuses on chemicals and PFCMs through three Acts of Parliament (Canadian Food Inspection Agency): the Food and Drug Act (FDA), the Consumer Packaging and Labelling Act (CPLA), and the Safe Foods for Canada Act (SFCA). The essence of these Acts is summed up in the first clause of Division 23, Part B of the FDA's Food and Drug Regulation:

No person shall sell any food in a package that may yield to its contents any substance that may be injurious to the health of a consumer of the food. (Government of Canada, 2018)

Division 23 itemizes specific substances and mixtures that are prohibited or limited and sets out labeling requirements. Toxicological analyses of substances are conducted under the Chemicals Management Plan. Health Canada's Health Products and Foods Branch (HPFB) and the Canadian Food Inspection Agency (CFIA) are responsible for the assessment of PFCM and the enforcement of regulations and standards (Blakney et al., 2014; Magnuson et al., 2013).

EPH and CFIA inspectors may use three types of documents that attest to materials' suitability for use with food: Letters of Acceptance (LOA) issued by the CFIA, Letters of No Objection (LONO) from the HPFB, and letters of guarantee (LOG) from manufacturers. Until 2014, the CFIA evaluated materials used by food processors under its authority, issued LOAs for approved products, and maintained a reference list of these products (Canadian Food Inspection Agency, 2015). This mandatory program is no longer active but LOAs and the reference list are still used by CFIA inspectors. LONOs are issued for products indicating acceptable conditions for using materials in contact with food. Manufacturers submitting applications for LONOs do so voluntarily. Suppliers' LOGs are legal documents indicating suitable uses for materials (Canadian Food Inspection Agency, 2017; Magnuson et al., 2013).

\section{Changes in federal legislation and regulation}

On 15 January 2019, many regulations under the CPLA will be consolidated within the SFCA. Health Canada is considering amending Division 23 to implement mandatory premarket assessments for food packaging materials (PackagingLaw. com, 2017).

\section{Policies, regulations, and management related to food establishments}

The Federal/Provincial/Territorial Food Safety Committee (FPTFSC), an interagency body, maintains the Food Retail and Food Services Code (FPTFSC Code) that serves as a blueprint for provincial, territorial, and local codes and guidelines (Health Canada and Bureau of Food Regulatory International and Interagency Affairs, 2011). The FPTFSC Code deals exclusively with food service and retail establishments covering chemical contamination, packaging, transportation, storage, and distribution of food (Federal/Provincial/Territorial Food Safety Committee, 2016). The FPTFSC Code's provision requiring the use of food-grade materials corresponds closely to Clause 1 of Division 23:

\section{Any material that does not yield any substance that may be injurious to the bealth of the consumer of the food. (Federal/Provincial/Territorial Food Safety Committee, 2016)}

The FPTFSC Code further states that food-grade packaging must be approved for use according to the CFIA's reference list or must have a LONO. LOGs are not mentioned, but consultations with inspectors indicate that they are sometimes requested. Plastic food containers (except those used for transporting food) and reusable packages are not included. Chemical contamination from metals, ceramics, and wood are well explained; however, contamination via contact with plastic is not mentioned. Definitions of food grade and the overall treatment of PFCAs differ across jurisdictions.

\section{Challenges}

Public health inspectors (PHIs) face an emerging issue of concern when dealing with the safe use of PFCAs. Clearer regulation and guidelines for PFCAs usage in food establishments will be helpful. However, three challenges need to be addressed to develop these regulations and guidelines.

\section{Information on contamination of food by chemicals migrating from PFCAs exists but is not easily accessed or used by practitioners}

Harmonized databases of toxicological and migration findings for many chemicals in PFCAs are maintained and used by regulators in many countries, including Canada. In Canada, this type of information has not yet informed tools such as guidelines or checklists used in EPH practice. Most data pertain to individual substances or to PFCM resins but not to the compounded forms often found in PFCAs. Many chemicals, including breakdown products and those inadvertently introduced during the manufacturing process, are not included (Muncke et al., 2017).

In addition, clear understanding of terminology is important. For example, food grade is often interpreted as safe for use with food; however, the term safe or food safe is accurate only within the context of the conditions of use (Roberie, 2017). Similarly, designations such as food safe, microwave safe, freezer safe, and dishwasher safe only apply to certain food-plastic combinations and conditions of use. For example, microwave-safe containers may leach chemicals if heated many times (Fasano et al., 2015; 
"Food safety. Microwaving food in plastic; dangerous or not?," 2006). Illustrations of safe uses of two PFCAs, plastic films and melamine dishware, are provided in Figure 1.

These information challenges can be addressed through evidence-based knowledge translation and hazard and risk assessments tailored for PFCAs. Together these can provide knowledge synthesis and prioritisation of issues to identify and address gaps. Current knowledge can also be used to develop rules of thumb such as recommending covering hot food with stainless steel instead of plastic given the understanding that heat is a major migration catalyst. The same knowledge can also be used to educate operators as part of the promotion of best practices. The Canadian Partnership for Children's Health and Environment has used this type of information to inform food preparation guidelines in childcare facilities since 2010. This organisation's handbook contains clear explanations and directions for heating in glass or metal containers and transferring foods and beverages to plastic after cooling (Canadian Partnership for Children's Health and Environment, 2010).

\section{Information gaps need to be addressed with contextualised research and regulatory tools}

Poor data on population-level exposures attributable to chemicals migrating from PFCAs into foods is probably the most important information gap. The retail node of the food chain is a potential point of contamination but foods sold and served are rarely tested for migrants. Chemical monitoring of the food supply takes place in agricultural and processing facilities under the auspices of CFIA inspection. Much of the research on migration does not use actual food, rather food simulants, such as cooking oils as a proxy for fatty foods.

Improving our understanding of the chemical safety of food at the point of sale or consumption requires research that could involve the EPH community because of its familiarity with the uses of PFCAs in food establishments. Studies in these areas could be included as part of a larger research

\begin{tabular}{|c|}
\hline PLASTIC FILMS \\
(polyethylene (PE), \\
polyvinyldine chloride $(P V d C)$ and \\
polyvinyl chloride $(P V C))$
\end{tabular}

Migration catalyst:

Heat, fatty foods (especially PVC)

Practice tips:

- In food service, use alternative inert materials (e.g., stainless steel) to cover hot foods.

- For fatty foods, PVdC appears to have lower migration rates.

Challenge:

- PVC is easiest to use (stretchy and clingy).

- Wraps are prevalent and it can be difficult to identify compounds used. agenda to improve knowledge about PFCA contents and migration risks.

\section{Canadian policy and regulation are dominated by nonmandatory provisions}

Within the LONO system only PFCMs submitted voluntarily by manufacturers are assessed. Tracking sources of materials without a listing or LONO can be difficult, and it may be impossible to identify hazards associated with some PFCAs. In addition, the FPTFSC Code specifies that LONOs or the CFIA reference list should be used to verify the safety of packaging but there are no provisions for other PFCAs. A large part of this challenge needs to be met by federal policy; however, better integration of EPH into the policy transmission chain could improve oversight.

\section{Conclusion}

Chemical risks associated with PFCAs have emerged as a concern, and current knowledge about this topic needs to be improved and contextualised to enhance EPH's inspection capacities. The numerous potential health risks associated with hazardous chemicals migrating from PFCAs into foods are associated with long-term exposures to small concentrations. Adverse health effects may become apparent only after a long period of time and tracing them back to a specific source can be difficult or impossible. PFCAs are ubiquitous throughout the food supply system, including food service and retail establishments. Thus, the EPH community is an important link in the chain of inspection ensuring food safety.

Several gaps must be addressed to provide clearer guidance to PHIs. Research could reduce information gaps such as the lack of data on concentrations of migrated chemicals in foods and consumers' uptake of these chemicals. Practice could be improved through the consistent use of tools such as LONOs, LOGs, and the CFIA reference list. Rules of thumb based on

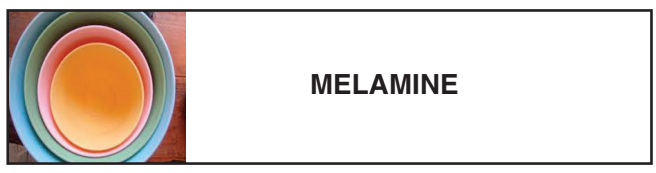

Migration catalysts:

Heat, contact time, acidic food, age of article

Practice tips:

- Use for serving only.

- Do not heat, including microwave.

- Avoid extended contact with hot or acidic food.

Challenges:

- Extensively used in care facilities where preheating and extended contact time with hot food is common

- Durable - one of few non-breakable alternatives to single-use items 
results from migration research could further guide PFCA use and the use of alternative materials. Promoting safer use of PFCAs must include education and engagement of operators. This means communicating information on the migration process and the health risks of consuming foods contaminated with migrated chemicals. It will also require providing clear instructions on the safe uses of PFCAs and alternative materials.

\section{References}

Blakney, J. F., Patterson, M. E., and Panjwani, J. 2014. Chapter 3. Canada. In: E. Kirchsteiger-Meier and T. Baumgartner (eds.) Global food legislation: An overview. Hoboken, NJ: Wiley-VCH Verlag.

Canadian Food Inspection Agency. 2010, Guide to food safety. Ottawa, ON: CFIA. Available at: http://www.inspection.gc.ca/ food/non-federally-registered/safe-food-production/guide/ eng/1352824546303/1352824822033

Canadian Food Inspection Agency. 2015. Healthy and safe food for Canadians framework [Online]. Available at: http://www.inspection.gc.ca/food/action-plan/framework/ eng/1385063041685/1385063100087 [accessed 29 October 2018].

Canadian Food Inspection Agency. 2017. Guidance for food establishments concerning construction materials and packaging materials and non-food chemicals [Online]. Available at: http://inspection. gc.ca/food/safe-food-production-systems/technical-references/ guidance/eng/1412187967735/1412187968391 [accessed 29 October 2018].

Canadian Partnership for Children's Health and Environment. 2010, Advancing environmental health in child care settings. A checklist for child care practitioners and public health inspectors. Toronto, ON: CPCHE. Available at: http://www.healthyenvironmentforkids.ca/sites/healthyenvironmentforkids.ca/files/CPCHEAdvEnvHealthChildCare-lowres.pdf

Diamond, J. M., Latimer, H. A., Munkittrick, K. R., Thornton, K. W., Bartell, S. M., and Kidd, K. A. 2011. Prioritizing contaminants of emerging concern for ecological screening assessments. Environ Toxicol Chem. 30(11): 2385-2394. doi: 10.1002/etc.667

Duffy, E., Hearty, A. P., McCarthy, S., and Gibney, M. J. 2007. Estimation of exposure to food packaging materials. 3: Development of consumption factors and food-type distribution factors from data collected on Irish children. Food Addit Contam. 24(1): 63-74. doi: $10.1080 / 02652030600865475$

Environment Canada, and Health Canada. 2008. Proposed risk management approach for phenol, 4,4'-(1-methylethylidene) bis (Bisphenol A). Chemical Abstract Service Registry number (CAS $\mathrm{RN})$ : 80-05-7. Ottawa, ON: Government of Canada. Available at: https://www.ec.gc.ca/ese-ees/6FA54372-A09E-45CD-8A5F39EBDD55D13A/batch2_80-05-7_rm_en.pdf

Fasano, E., Cirillo, T., Esposito, F., and Lacorte, S. 2015. Migration of monomers and plasticizers from packed foods and heated microwave foods using QuEChERS sample preparation and gas chromatography/mass spectrometry. Food Sci Technol. 64(2): 1015-1021. doi: https://doi.org/10.1016/j.lwt.2015.06.066

Federal/Provincial/Territorial Food Safety Committee. 2016. Food retail and food services code. Whitehorse, YK: Yukon Health and Social Services. Available at: http://www.hss.gov.yk.ca/pdf/foodservicescode.pdf

Food safety. Microwaving food in plastic; dangerous or not? 2006. Harv Womens Health Watch. 13(11): 6-7.
Geueke, B., Wagner, C. C., and Muncke, J. 2014. Food contact substances and chemicals of concern: A comparison of inventories. Food Addit Contam Part A Chem Anal Control Expo Risk Assess. 31(8): 1438-1450. doi: 10.1080/19440049.2014.931600

Government of Canada. 2018. Food and Drug Regulations (C.R.C., c. 870). Part B foods, Division 23 Food packaging materials [Online]. Available at: https://laws-lois.justice.gc.ca/eng/regulations/c.r.c.,_c._870/page-79.html\#docCont [accessed 29 October 2018].

Grob, K., Camus, P., Gontard, N., Hoellinger, H., Joly, C., Macherey, A. C., Masset, D., Nesslany, F., Régnier, J. F., Riquet, A. M., Saillard, P., and Ribera, D. 2010. Need for a better safety evaluation of food contact materials produced from resins. Food Control. 21(5): 763-769. doi: https://doi.org/10.1016/j.foodcont.2009.11.006

Groh, K. J., Backhaus, T., Carney-Almroth, B., Geueke, B, Inostroza, P. A., Lennquist, A., Maffini, M., Leslie, H. A., Slunge, D., Trasande, L., Warhurst, M., and Muncke, J. 2018. Chemicals associated with plastic packaging: Inventory and hazards. PeerJ Preprints. 6: e27036v27031. doi: 10.7287/peerj.preprints.27036v1

Hahladakis, J. N., Velis, C. A., Weber, R., Iacovidou, E., and Purnell, P. 2018. An overview of chemical additives present in plastics: Migration, release, fate and environmental impact during their use, disposal and recycling. J Hazard Mater. 344: 179-199. doi: 10.1016/j.jhazmat.2017.10.014

Halden, R. U. 2010. Plastics and health risks. Annu Rev Public Health. 31: 179-194. doi: 10.1146/annurev.publhealth.012809.103714

Halden, R. U. 2015. Epistemology of contaminants of emerging concern and literature meta-analysis. J Hazard Mater. 282: 2-9. doi: 10.1016/j.jhazmat.2014.08.074

Health Canada, and Bureau of Food Regulatory International and Interagency Affairs. 2011. Interagency program [Online]. Available at: https://www.canada.ca/en/health-canada/corporate/about-healthcanada/branches-agencies/health-products-food-branch/food-directorate/bureau-food-regulatory-international-interagency-affairs/ interagency-program.html [accessed 29 October 2018].

Holmes, M. J., Hart, A., Northing, P., Oldring, P. K., Castle, L., Stott, D., Smith, G., and Wardman, O. 2005. Dietary exposure to chemical migrants from food contact materials: A probabilistic approach. Food Addit Contam. 22(10): 907-919. doi: 10.1080/02652030500307172

Jenner, T., Elliott, M., Menyhart, C., and Kinnear, H. 2005. The HACCP advantage guidebook. Toronto, ON: Ontario Ministry of Agriculture and Food. Available at: http://www.ontla.on.ca/ library/repository/mon/10000/251324.pdf

Kao, Y.-M. 2012. A review on safety inspection and research of plastic food packaging materials in Taiwan. J. Food Drug Anal. 20(4): $734-743+980$.

Lechevalier, V. 2016. Chapter 8. Packaging: Principles and technology. In: R. Jeantet, T. Croguennec, P. Schuck and G. Brulé (eds.) Handbook of food science and technology 2: Food process engineering and packaging. Hoboken, NJ: John Wiley and Sons.

Magnuson, B., Munro, I., Abbot, P., Baldwin, N., Lopez-Garcia, R., Ly, K., McGirr, L., Roberts, A., and Socolovsky, S. 2013. Review of the regulation and safety assessment of food substances in various countries and jurisdictions. Food Addit Contam Part A Chem Anal Control Expo Risk Assess. 30(7): 1147-1220. doi: 10.1080/ 19440049.2013.795293

Marsh, K., and Bugusu, B. 2007. Food packaging-Roles, materials, and environmental issues. J Food Sci. 72(3): R39-R55. doi: 10.1111/j.1750-3841.2007.00301.x 
Muncke, J., Backhaus, T., Geueke, B., Maffini, M. V., Martin, O. V., Myers, J. P., Soto, A. M., Trasande, L., Trier, X., and Scheringer, M. 2017. Scientific challenges in the risk assessment of food contact materials. Environ Health Perspect. 125(9): 095001. doi: 10.1289/ehp644

Oldring, P. K., O’Mahony, C., Dixon, J., Vints, M., Mehegan, J., Dequatre, C., and Castle, L. 2014. Development of a new modelling tool (FACET) to assess exposure to chemical migrants from food packaging. Food Addit Contam Part A Chem Anal Control Expo Risk Assess. 31(3): 444-465. doi: 10.1080/19440049.2013.862348

PackagingLaw.com. 2017. Canada considering positive list system for food-contact materials. Washington, DC: Keller and Heckman LLP. Available at: http://www.packaginglaw.com/news / canada-considering-positive-list-system-food-contact-materials

Rayner, M., and Scarborough, P. 2005. The burden of food related ill health in the UK. J Epidemiol Community Health. 59(12): 1054-1057. doi: 10.1136/jech.2005.036491

Roberie, L. 2017. Is food-grade always food-safe? Food manufacturing. Food Safety Tech. Available at: https://foodsafetytech.com/column/food-grade-always-food-safe/
Rossi, M. S., and Blake, A. 2014, The plastics scorecard: Evaluating the chemical footprint of 1104 plastics, Version $1.0 \mathrm{ed}$. Somerville, MA: Clean Production Action. Available at: https://www.bizngo.org/ sustainable-materials/plastics-scorecard

Singh, P., Wani, A., and Langowski, H.-C. (eds.). 2017. Food packing materials: Testing and quality assurance. London, UK: CRC Press.

U.S. Department of Health and Human Services. 2008. Managing food safety: A regulator's manual for applying HACCP principles to risk- based retail and food service inspections and evaluating voluntary food safety management systems. College Park, MD: U.S. Department of Health and Human Services, Food and Drug Administration. Available at: https://www.fda.gov/downloads/ food/foodsafety/retailfoodprotection/managingfoodsafetyhaccpprinciples/regulators/ucm078159.pdf

Vitrac, O., and Goujon, A. 2014. Food packaging: new directions for the control of additive and residue migration. In: T. Hamaide, R. Deterre and J. F. Feller (eds.) Environmental impact of polymers (pp. 273-308). London, UK: ISTE Ltd. 